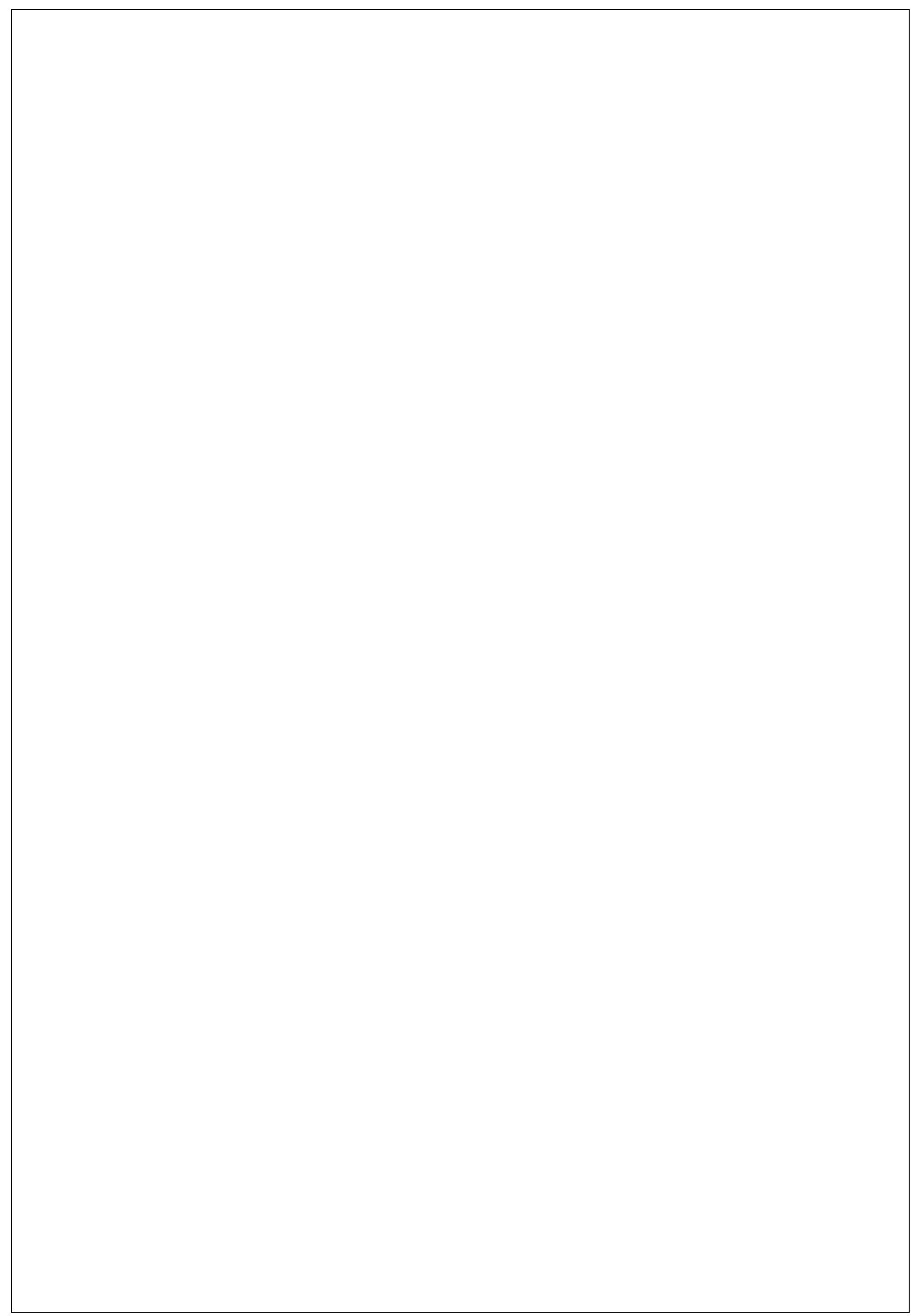


ISSN 2178-6925

\title{
PERSPECTIVA PSICANALÍTICA DA ANOREXIA NERVOSA
}

PSYCHOANALYTIC PERSPECTIVE OF ANOREXIA NERVOSA

\begin{abstract}
Ana Karoline de Souza Pereira
Graduanda do curso de Psicologia da Faculdades Alfa Unipac Teófilo Otoni - Minas

Gerais, E-mail: aksouza358@gmail.com

Paula Lins Khoury

Psicóloga, especialista em Psicanálise e Laço Social, pós graduada em docência no ensino superior, professora, supervisora de estágio e coordenadora do curso de Psicologia da Faculdade Alfa Unipac, Conselheira do XV e VXI Plenário do Conselho Regional de Psicologia - MG.

E-mail:paulalinskhoury@yahoo.com.br
\end{abstract}

Recebido: 16/06/2021 - Aceito: 18/06/2021

\section{Resumo}

Este estudo ocupa-se da perspectiva psicanalítica frente à Anorexia Nervosa, conhecida como um sintoma alimentar que tem como característica principal a alteração em relação ao peso e a imagem corporal, acompanhada intimamente do medo excessivo de engordar. O objetivo do estudo é descrever a Anorexia Nervosa numa perspectiva psicanalítica. Para tanto, realizou-se pesquisa bibliográfica de cunho descritivo e abordagem qualitativa, revisando publicações cientificas no período dos últimos 10 anos, salvo os clássicos. Os resultados apontam elaborações acerca da Anorexia Nervosa apresentar fatores psicológicos, o que a torna praticável, isto é, ela tem o propósito de realizar algo que não seja apenas o quadro de emagrecimento, ou seja, o autor Sigmund Freud aponta nas relações interpessoais, o outro é colocado como objeto libidinal. O que ocorre é que, ao se apresentar não completamente disponível para o sujeito, a parcela libidinal é retirada desta relação. É possível afirmar que a etiologia desse caso ainda é desconhecida, porém autores tais como Sigmund Freud, Melanie Klein, Jaques Lacan, citam diversos fatores intervenientes e condições facilitadoras para o desenvolvimento de tal transtorno, a título de exemplo, a constituição subjetiva, protestos e impasses na separação com o Outro, bem como, a identificação com o objeto. Esse trabalho se norteou de estudos sobre a Anorexia Nervosa ao longo da história, o processo de constituição subjetiva e relações familiares, e a estruturação dos sintomas da Anorexia Nervosa. Entende-se que tais aspectos são fatores associados e determinantes quando relacionados a estruturação desse transtorno. Por conseguinte, o sintoma da anorexia aponta a maneira do sujeito tentar lidar com a falta do Outro, buscando essa carência posteriormente em situações substitutivas à vivenciada enquanto criança. 
Palavras chave: Anorexia Nervosa; constituição subjetiva; identificação; separação do Outro. 


\section{1/02}

ISSN 2178-6925

\section{Abstract}

This study deals with the psychoanalytic perspective with facing Anorexia Nervosa, known as an alimentary symptom whose main characteristic is the change of weight and body image, closely accompanied by excessive fear of gaining weight. The purpose of the study is to describe Anorexia Nervosa from a psychoanalytic perspective. To this end, a bibliographic research of a descriptive and qualitative approach was carried out, reviewing scientific publications over the last 10 years, excepting the classics. The results point out elaborations about Anorexia Nervosa presenting psychological factors, which makes it practicable, namely, it has thepurpose of accomplishing something that is not only the picture of weight loss, the author Sigmund Freud points out in interpersonal relationships, the other is placed asa libidinal object. What occurs is that, when it is not completely available to the subject, the libidinal portion is removed from this relationship. It is possible to affirm that the etiology of this case is still unknown, but authors such as Sigmund Freud, Melanie Klein, Jaques Lacan, mention several intervening factors and facilitating conditions for the development of such disorder, as an example, the subjective constitution, protestsand impasses in the separation with the Other, as well as, the identification with the object. This work was guided by studies on Anorexia Nervosa throughout history, the process of subjective constitution and family relationships, and the structuring of symptoms of Anorexia Nervosa. It is understood that such aspects are associated anddetermining factors when related to the structure of this disorder. Consequently, the symptom of anorexia points to the subject's way of trying to deal with the Other's lack, seeking this lack later in situations that substitute the one experienced as a child.

Keywords: Anorexia Nervosa; subjective constitution; identification; separation from the other.

\section{Introdução}

Compreendendo que pesquisa e clínica em Psicanálise se fazem em um só tempo, a clínica dos sintomas alimentares é fonte e alvo de muitos questionamentos e tentativas de construções para orientações a respeito da compreensão e atendimento nesta área. Dentre os transtornos alimentares, a Anorexia Nervosa é conhecida como um sintoma alimentar, que apresenta uma disparidade em relação ao peso e a imagem corporal, acompanhada intimamente do medo excessivo de engordar.

É possível afirmar que são múltiplos os fatores intervenientes e condições facilitadoras para o desenvolvimento de tal sintoma, como a própria constituição subjetiva, protestos e impasses na separação com o Outro, bem como, o processo de identificação com o objeto. "Devemos colocar a identificação anoréxica, não mais como um sintoma social [...], mas interrogar [...], qual pode ser sua ligação com o 
Outro além da identificação anoréxica." (VIGANO, 2012, p.222). Em vista disso, este trabalho irá delimitar seus estudos especificamente em descrever a Anorexia Nervosa numa perspectiva psicanalítica, tendo como objetivo retratar a Anorexia Nervosa ao longo da história, assim como também o processo de constituição subjetiva e relações familiares, e a estruturação dos sintomas da Anorexia Nervosa, usufruindo o seu embasamento na teoria no fundador da Psicanálise, Sigmund Freud.

Desta forma, surgem indagações acerca do que contribui para a manifestação da anorexia. Afinal, o que leva o sujeito a estar anoréxico? Quais aspectos estão envolvidos nesse contexto? Por que as relações sociais afetam tanto a constituição subjetiva do indivíduo? Buscando responder esses questionamentos, esse trabalho se norteará da seguinte pergunta problema: Quais os fatores psíquicos contribuem para o desenvolvimento da Anorexia Nervosa a partir da leitura psicanalítica?

Com base nas interrogações levantadas, espera-se que a questão principal desse trabalho seja organizada de forma compreensível e coesa, a fim de apresentar conceitos pertencentes a temática com a respectiva fundamentação da obra psicanalítica. Da mesma forma, acredita-se que os estudos sobre a Anorexia Nervosa ao longo da história, o processo de constituição subjetiva e relações familiares, e a estruturação dos sintomas da Anorexia Nervosa sejam de extremo valor para que este trabalho alcance desfecho em sua proposta.

Portanto, identificar os fatores psíquicos que contribuem para o desenvolvimento da Anorexia Nervosa a partir de uma leitura psicanalítica, mostra-se de suma relevância para o meio acadêmico, científico e profissional, pois poderá servir de fonte de leitura científica, contribuindo para a condução de casos e discussões a respeito desta clínica.

Em seguida o presente trabalho apresentará a Anorexia Nervosa ao longo da história, assim como o processo de constituição subjetiva e relações familiares, e por último a estruturação dos sintomas da Anorexia Nervosa.

\section{Metodologia}

Quanto aos procedimentos técnicos, este trabalho empregará o método de revisão bibliográfica como tipo de pesquisa para discorrer o tema supracitado. Será utilizado a metodologia descritiva no que diz respeito ao estudo e interpretação dos 
objetivos, e quanto à abordagem, adotará o tipo qualitativo no que tange a análise e interpretação dos conteúdos apresentados, tendo como descritores a Anorexia Nervosa, constituição subjetiva, identificação e separação do Outro.

Este trabalho utilizará materiais reconhecidos no meio cientifico, especificamente obras clássicas como as de Sigmund Freud, Melanie Klein, Jaques Lacan entre outros, que serão de suma importância para nortear o trabalho. E como fonte de pesquisa, adotará livros e artigos científicos encontrados em plataformas eletrônicas, com publicações entre os anos de 2010 a 2020, com exceção de materiais que possuírem dados de extrema relevância e indispensáveis para a pesquisa.

\section{Revisão de literatura}

\subsection{A Anorexia Nervosa ao longo da história}

O jejum auto imposto tem uma longa história na existência da humanidade, uma vez que, esse ato era bastante praticado por povos da antiguidade com a finalidade de práticas religiosas e curativas. Hipócrates (460 a.C.-370a.C, apudWeinberg, 2010, p.226), costumava orientar tal pratica para o tratamento de doenças.Desta forma, a abstinência alimentar, penitências e redução das horas de sono eramconsiderados rituais de purificação. Entretanto, mais tarde começaram a surgir indagações acerca de que estes atos poderiam restar associados a transtornos alimentares.

Entretanto, esses hábitos religiosos continuaram a ganhar força durante o período medieval e de forma mais rigorosa. As práticas de purificação, eram feitas em defesa da virgindade ou castidade. Sendo assim, Fendrik (1997), postula que nesse cenário começaram a se apresentar as santas jejuadoras que tiveram uma maior atuação entre os séculos XIII e XIV. Do mesmo modo, o autor ressalta também que durante esse período ocorreu uma eminente epidemia do comportamento anoréxico.

Muitas foram as santas jejuadoras, que por um longo período de tempo foram vistas como modelo, na qual, motivaram outras moças a se espelharem e começarem a reproduzir os mesmos comportamentos de recusa a alimentação. Dentre tantas moças que praticaram o jejum auto imposto, santa Vilgefortis (do latim virgo fortis, virgem forte) foi uma das precursoras dessa prática. Segundo Fendrik(1997), Vilgefortis viveu entre os séculos VIII e X, e a sua prática começou a partir do momento 
em que a santa soube dos planos de seu pai, um tirano pagão e cruel, que obrigaria a moça a se casar com o rei de Sicília. Em vista disso, Vilgefortis ficou apavorada porque nessa época já havia feito voto de castidade. Portanto, para resguardar sua virgindade e seu voto, iniciou um severo jejum, ao mesmo tempo rogou a Deus para ajudá-la lhe tirando sua beleza. Com isso, o rei de Sicília assustado com a magreza de Vilgefortis desistiu do casamento e seu pai furioso com o acontecido, mandou crucifica-la.

Da mesma forma, segundo Radi (2015) a santa Clara de Assis, também praticava grande expressividade nos atos de penitência e privação a alimentação. $A$ santa que viveu entre os anos de 1193 a 1253, desde a infância teria revelado grande fé religiosa. Desse modo, na adolescência se encantou pelas pregações de Francisco, o futuro são Francisco de Assis, e começou a segui-lo. O autor aponta que santa Clara dedicou sua vida a caridade e ao trabalho, na qual, sempre mostrou persistência e dedicação em suas tarefas. Contudo, a jovem viveu durante 28 anos doente em razão dos jejuns auto impostos e as penitências, apesar de sempre mencionar a si mesma como forte e saudável como justificativa para continuar a jejuar todos os dias. Por meio de tais condutas como a recusa a alimentação e severidade consigo mesma, é possível atribuir esse sintomas ao quadro e ao comportamento anoréxico dos dias atuais.

Assim também praticava a santa Catarina de Siena, que viveu entre os anos de 1347 a 1380. A jovem viveu confinada em seu quarto rezando a luz de velas dos 12 aos 16 anos, saía exclusivamente para ir à igreja e conversava com os familiares apenas o necessário. Quando iniciou as privações de alimentação, comia somente ervas cruas e pouquíssimos pedaços de pão e por isso era forçada a fazer sua alimentação de maneira mais apropriada. Porém, ao ser pressionada, deixava de consumir o pouco que ainda ingeria, ou recorria à indução de vômitos. Santa Catarina também se propôs a reduzir as horas de sono, chegando ao ponto de repousar-se apenas durante 1 hora a cada dois dias, bem como, açoitava seu próprio corpo com uma corrente de ferro, três vezes ao dia. Seus atos de recusa a alimentação foram tão exagerados, que a jovem estendeu o jejum por dois meses e meio, desde a quaresma até ascensão, e apesar de não ingerir nenhuma bebida ou comida, santa Catarina apresentava-se muito ativa. Segundo Fendrik (1997), esta santa foi escolhida 
por outras tantas santas como modelo. Santa Maria Madalena de Pazzi, é um exemplo de suas seguidoras.

Santa Maria Madalena de Pazzi viveu entre os anos de 1566 a 1607 ao entrar para o convento e receber os votos, depois de um ano mudou seu nome de batismo Catarina, para Maria Madalena. Dizendo ser orientada por Deus, passou a delimitar sua alimentação apenas a pão e água, com exceção aos domingos que comia somente os restos de comida deixado pelas irmãs. Consequentemente, suas superiores passaram a força-la a se alimentar, mas quando confrontada a jovem se colocava a provocar vômitos. Porém, era pega repetidamente em alguns momentos comendo as escondidas enormes quantidades de alimentos. Em vista disso, através dos atos da moça como comportamentos purgativos, resistência a alimentação e hábitos bulímicos, é de se indagar se nos dias atuais um clínico não lhe daria um diagnóstico de Anorexia Nervosa, do tipo purgativo. Característica essa, que será explanada mais adiante nesse trabalho. (WEINBER, 2010)

Segundo Weinberg (2010), outro fator histórico que é possível destacar foi a publicação do médico inglês Richard Morton em 1691 que parece ter registrado as primeiras descrições da Anorexia Nervosa. Em sua obra Tisiologia, abordou sobre a doença da consumação, na qual as descrições acerca dos quadros assemelham a Anorexia Nervosa dos dias atuais. Dentre as descrições apontadas para atrofia nervosa, nome dado à doença naquela época, os indícios eram caracterizados por três sintomas predominantes, sendo eles: emagrecimento com perdas de tecidos corporais, amenorreia e perda de apetite.

De acordo com Weinberg (2010), nas publicações de William Gull em 1868, a recusa a alimentação estava relacionada a doença mental ou doença orgânica como diabetes, câncer e até mesmo tuberculose. Porém, Gull reconheceu que se tratava de um processo independente, sendo vista como autônoma. Logo, denominou a doença pelo nome de apepsia hysteric, mas, adiante, percebeu que o termo anorexia que significa falta de apetite, era melhor que apepsia que significa indigestão, pelo fato de que nesse distúrbio o alimento poderia ser ingerido, com exceção aos últimos estágios da doença em que não há consumo de alimento.

No fim do século XIX os médicos ainda estavam apegados a ideia de fatores físicos ligados a Anorexia Nervosa, apesar de estarem atentos aos processos psíquicos envolvidos nela. Desta forma, os psiquiatras e neurologistas começaram a 
se preocupar com os fatores da história de vida dos pacientes, com intuito de descobrir as causas emocionais. Dentre eles, Sigmund Freud foi de grande relevância para o entendimento dessa doença, na qual classificou a Anorexia Nervosa como uma neurose, e acreditava que o apetite tinha relação com conteúdo simbólico da psique humana. Os questionamentos de Freud(1950) a respeito da anorexia trouxeram um aspecto inovador, ao perguntar exatamente o significado da falta de apetite e o que a anoréxica realmente se recusa ao apresentar tal sintoma.

Para melhor compreensão dessa temática, o presente trabalho estará discorrendo na próxima sessão a respeito do processo de constituição subjetiva e relações familiares.

\subsection{Processo de Constituição subjetiva e relações familiares}

Muitos foram os autores que marcaram o século XX com grandes mudanças e descobertas no que se refere ao pensamento humano, na qual Freud com a criação da teoria psicanalítica e a subversão da conceituação a respeito do inconsciente. $O$ estudioso Sigmund Freud foi o responsável por uma nova elaboração conceitual da sexualidade humana e da presença dela desde a infância, não sendo bem aceito pela comunidade cientifica onde o autor tornou-se vítima de inúmeras críticas e preconceitos.

O pai da psicanálise aponta que o corpo da criança é fonte de estimulação e mediação com o mundo interno e externo, nomeando de libido a energia sexual que atuará em direção a descarga máxima e tensão mínima. Energia essa, que se encontra desorganizada no corpo da criança e localizada em certas partes erógenas que só posteriormente acolhe uma organização que a direcionará a realização da satisfação sexual envolvendo nãos mais fragmentos do corpo. Segundo Freud (1905), as fases da organização da libido são ocasiões em que certas pulsões associadas a determinada parte específica do corpo da criança, atuam com mais vantagens em relação as outras. Entretanto, não significa que as pulsões não possam estar em atuação ao mesmo tempo, não sendo necessário a superação da fase anterior para a implicação de outra.

Consequentemente, faz-se necessário entender como se destina essas pulsões e quais são as fases, que foram denominadas de: Oral, se estendendo pelo 
primeiro ano e meio de vida e Anal - vivenciada pelo ano e meio seguinte. Logo após ocorre a vivência da fase Fálica, que tem início por volta dos 3 anos, sucedendo o período de Latência e a fase Genital. Porém, para um maior desenvolvimento desse trabalho, mostra-se de grande importância que seja abordada mais especificamente a fase oral, pois é nela que Freud vai apontar as principais relações com os sintomasda anorexia.

O ser humano ao nascer, possui a característica da dependência total de alguém que o cuide para que possa sobreviver, sendo um sujeito totalmente dependente do outro. Entretanto, no decorrer do desenvolvimento da vida e das relações humanas estabelecidas, esse sujeito vai adquirindo habilidades para conduzir sua própria vida de maneira a não depender do outro de maneira tão visceral.

\begin{abstract}
A primeira dessas organizações sexuais pré-genitais é a oral [...] nela, a atividade sexual ainda não se separou da nutrição, nem tampouco se diferenciaram correntes opostas em seu interior. $O$ objeto de uma atividade é também o da outra, e o alvo sexual consiste na incorporação do objeto modelo do que mais tarde irá desempenhar, sob a forma da identificação, um papel psíquico tão importante. (FREUD, 1905, p.187)
\end{abstract}

A alimentação e a proteção são fatores de necessidades básicas da criança, e é por meio da amamentação que a mesma obtém suas primeiras experiências de satisfação. Em vista disso, é por intermédio da boca que suas primeiras experiências satisfatórias e afáveis são vivenciadas. Essas vivências são conservadas na memória da criança e sempre que se fizer necessário satisfazer tais impulsos novamente, elas serão evocadas. Nessa etapa o objeto de desejo primordial é o seio materno que vem acompanhado do olhar, proteção, voz, caricias e calor. Isso fica melhor explicitado no trecho a seguir:

Há muitas outras ocasiões, além do contato com o seio, em que o bebê
percebe e registra inconscientemente o amor, a paciência e a compreensão
da mãe - ou o seu oposto. Como já observei, os primeiros sentimentos estão
ligados a estímulos internos e externos - agradáveis ou desagradáveis - e
estão associados a fantasias. A maneira como o bebê é tratado desde a hora
do parto pode deixar impressões permanentes em sua mente (KLEIN,1996,
p.338).

No entanto, a mãe tem outros fatores em sua vida a qual seu desejo irá direcionar, se fazendo ocasionalmente indisponível, acarretando na criança suas primeiras frustrações e contato com a falta. A partir de então, a criança busca novas formas de substituição do seio, como o dedo, a língua, a chupeta entre outros objetos. 


\section{1/02}

ISSN 2178-6925

"Podemos ver o chuchar, no qual a atividade sexual, desligada da atividade de alimentação, renunciou ao objeto alheio em troca de um objeto situado no próprio corpo" (FREUD,1905, p.187).

Para a psicanálise, esse parece ser o ponto de partida da anoréxica, na qual o sujeito tende a arriscar a própria vida para desprender-se da superfície materna. "Procurando conservar o seu vazio diante de Outro que o preenche, um outro que o asfixia com seu nutrimento, para separar-se e nutrir-se de nada" (VIGANÒ, 2010, p. 218). Segundo Viganò (2010), as anoréxicas não caminham na direção da mudança de objetos, mas fixam-se em um objeto que é o oral, ao invés de mudar o objeto mudam o nome do objeto, mantendo-se aprisionado ao infantil, realizando a satisfação no próprio corpo. Isso pode ser notado justamente quando os sintomas tendem a aparecer na adolescência, em que o corpo continua em sua aparência infantil, pequeno e tentando recusar a caracterização sexual genital, geralmente esperado nesta fase do desenvolvimento. Partindo desse ponto de vista, observa-se a relevância da experiência do encontro com a falta, ruptura, o desmame e a separação da mãe, seja física ou simbólica, para possibilitar ao sujeito caminhar na sua própria constituição subjetiva.

Visando elucidar alguns aspectos que podem estar envolvidos na construção do sintoma da Anorexia Nervosa, faz-se necessário mencionar alguns processos psíquicos importantes para a compreensão do sujeito que tal transtorno acomete.

Nota-se nas obras psicanalíticas inúmeras discussões referentes ao conceito de sujeito, evidenciando que fartas circunstancias podem interferir direto ou indiretamente no processo de constituição subjetiva do indivíduo.

Segundo Ogden (1996), o sujeito não pode se constituir sozinho, o progresso da subjetividade necessita de experiências especificas de intersubjetividade. Sendo assim, os processos psíquicos que envolvem o espaço intersubjetivo do indivíduo são permeados por quadros psicológicos que inclui a díade, mãe-bebê. Em razão disso, Winnicott (1983), aponta que a constituição de si- mesmo parte da vivência inicial do

elo inter- relacional humano, na qual, para que o bebê obtenha sua própria subjetividade é necessário a presença de carga afetiva do outro, o olhar constante do outro, acolhendo aquele infante primitivo Ihe dando significado do vir a ser no mundo.

Consequentemente, pode-se perceber a grande influência familiar para o processo de subjetivação do indivíduo, uma vez que, é nesse grupo que o sujeito tem 


\section{1/02}

ISSN 2178-6925

o seu primeiro contato ao nascer e ao longo de sua vida é afetado por diversos conteúdos e ideologias vivencia dos nesse meio. Dessa maneira, Passos e Polak (2004), mencionam a existência de um psiquismo familiar, tendo sua própria herança geracional, na qual, é constituído por conteúdos intrapsíquicos oriundos de integrantes individuais do grupo, onde cada indivíduo exerce influência e ao mesmo tempo é influenciado. Em razão disso, "o processo de subjetivação é forjado nessa relação dialética entre o que é transmitido e o que é transformado" (Magalhães e FeresCerneiro, 2005, p.29).

Entretanto, não só o meio familiar influencia nesse processo, da mesma maneira, o meio social em que o indivíduo está inserido intervém direto ou indiretamente em tal constituição. Assim, esse sujeito necessita ser sustentado pela composição familiar e social para se constituir enquanto ser humano. É indispensável essa ligação com o outro, pois a mesma desempenha de forma significativa contribuições na formação subjetiva. Desse modo cabe mencionar que, "sem isso ele não só não se tornará humano [...] como tampouco se manterá vivo: sem a ordem familiar e social, o ser da espécie humana morrerá" (Elia, 2004, p.39).

Cabe ainda frisar a relevância do processo de identificação para o sujeito que está se constituindo, na qual a identificação é uma forma de expressão de vínculo afetivo onde o indivíduo se espelha assimilando aspectos e características do Outro e introjetando para si parte do objeto. Importante ressaltar que neste processo, o que é introjetado e catexizado são as representações psíquicas do objeto, ou seja, pensamentos, lembranças e fantasias a seu respeito, e não o objeto em si.

Segundo Brenner (1987), o processo de identificação revela-se como o "ato ou processo de tornar-se semelhante a algo ou alguém, em um ou diversos aspectos do pensamento ou comportamento" (p.56). Desse modo, o autor afirma ainda, que o sujeito aprende comportamentos através da identificação, podendo ser citado como exemplo, o fato da aprendizagem da linguagem, gostos ou até mesmo o fato de expressar ou reprimir impulsos instintivos. Em vista disso, convém apontar:

Observamos, assim, que a identificação exerce sua função no desenvolvimento do ego em mais de um aspecto. Acima de tudo, é parte inerente ao relacionamento do indivíduo com um objeto intensamente catexizado, em particular nos primórdios da vida. Além disso, registramos a tendência à identificação com um objeto admirado embora odiado. Finalmente, há o fator que mencionamos por último, segundo o qual a perda do objeto intensamente catexizado leva, em maior ou menor grau, à identificação com o objeto perdido (BRENNER, 1987, p.60). 


\section{1/02}

ISSN 2178-6925

Dessa maneira, nota-se que para se constituir enquanto sujeito é fundamental que ele seja atravessado pelos significantes do Outro. Entendendo que este Outro é o local a quem ele dirige a fala, a qual ele se identifica, mas também se diferencia. Quando isso não ocorre, mantendo-se preso no significante primordial, ocorre uma certa dependência do objeto identificado.

Consequentemente, é possível afirmar que a constituição subjetiva ocorrerá mediante variáveis de fatores, que se inter-relacionam configurando um processo fortemente dialético e dinâmico fundamental para a o processo de subjetivação e singularidade do sujeito no campo do seu próprio desejo e também do Outro.

\subsection{Estruturação dos sintomas da Anorexia Nervosa}

A Anorexia Nervosa tem como característica principal uma discrepância em relação ao peso e a imagem corporal, acompanhada intimamente do medo excessivo de engordar. As pessoas com tal diagnóstico apresentam uma grande recusa em manter um grau saudável em comparação ao peso, apresentando restrição alimentar e /ou uso de laxantes, provocações de vômitos e até mesmo o excesso de exercícios físicos. Desse modo, julga-se que a anoréxica apresenta tanto medo com relação ao engordar que a mesma não come na presença de outras pessoas, e aos poucos ela vai se isolando, empregando inúmeros mecanismos para esconder das pessoas a sua volta, mentindo que já comeu ou garantindo que comerá mais tarde. Por fim, se afasta constantemente na tentativa de evitar cobranças alimentares provenientes de outras pessoas. Afirmam Busse e Silva (2004) que a Anorexia Nervosa acomete indivíduos na puberdade, e que sua ocorrência é de oito a dez vezes maior em mulheres que em homens.

A respeito de possíveis causas para a Anorexia, pode-se afirmar que não existe uma única e exclusiva causa para o desenvolvimento deste sintoma, mas existem diversos fatores intervenientes e condições facilitadores, como, dificuldades para o desempenho autônomo e formação da própria identidade, expectativas pessoais muito altas, autoestima frágil, dificuldades em aceitar à separação, bem como, grande necessidade de aprovação externa e adequação aos desejos dos outros, resultando em um Eu vulnerável e recusa à sexualidade genital. 


\title{
2021/02
}

ISSN 2178-6925

Faz-se necessário diferenciar os dois tipos de anorexia nervosa conforme o trecho a seguir:

\begin{abstract}
Tipo Restritivo: durante o episódio atual de anorexia nervosa, a pessoa não se envolveu regularmente em um comportamento de alimentação compulsiva ou purgação (isto é, vômito auto-induzido ou uso indevido de laxantes, diuréticos ou enemas). Tipo Compulsão Periódica/Purgativo: durante o episódio atual de anorexia nervosa, a pessoa envolveu-se regularmente em um comportamento de alimentação compulsiva ou purgação (isto é, vômito auto-induzido ou uso indevido de laxantes, diuréticos ou enemas) (KAY; TASMAN, 2002, p.392).
\end{abstract}

Torna-se importante frisar que o tratamento se configura por uma equipe multidisciplinar e interdisciplinar, na qual este deve ser pautado, dependendo da gravidade do quadro, incialmente na normalização nutricional, justamente com o cuidado psíquico. $\mathrm{O}$ intuito, neste princípio, é retirar a paciente da zona de risco de vida. Essa fase engloba a recuperação nutricional que pode ser relacionada com o uso de fármacos e psicoterapia.

Ademais, é pode ser também citado a ocorrência da recusa do alimento como sendo um comportamento de protesto ou vingança. Nesse sentido, cabe apontar que:

A anorexia surge como um sintoma que traz em si uma tentativa de separação
do Outro, em que o não, o comer nada da anorexia evidencia a dimensão do
desejo daquela demanda. E mais, acrescentam, que existe "uma diferença
entre capricho e desejo, entre o 'não' como possibilidade de expressão
subjetiva e a radicalidade do nada, entre um movimento que visa o
distanciamento do Outro e uma outra manobra que requer sua presença
como refém do sujeito" (SILVA; BASTOS, 2006, p.15). Assim, quando a anoréxica se recusa a comer, ela está efetivamente, ressignificando a falta que o outro tentou preencher ofertando-Ihe alimentos. Lacan (1995), compreende a anorexia como um comer nada ao invés do não comer. O comer nada refere-se à possibilidade de introduzir uma falta no outro, para contrapor o investimento ou falta dele que pode ser sufocante. Realiza-se então uma parceria entre a anorexia com este nada. A recusa de alimento mostra-se no centro do desejo, na tentativa de provocar um corte em relação ao Outro. Logo, isso fica melhor explicitado no trecho a seguir: 


\begin{abstract}
Diante da angústia por não saber o que o sujeito lhe está demandando, por não entender o que o choro do bebê significa, o Outro responde com o alimento, ou seja, reduz a falta à falta de alimento. $O$ sujeito, massacrado pelos cuidados do Outro, encontra como solução, como via de sustentação do desejo, a recusa do objeto oral. O sujeito propõe que o Outro busque um objeto de desejo além dele, fora dele, porque assim ele próprio encontrará o rumo do desejo. Recusar o alimento é, portanto, uma forma de assegurar que algo falta ao Outro, que a falta não pode ser reduzida à falta de alimento, e mais, que a falta é estrutural, não podendo ser suprimida por nenhum objeto (SILVA; BASTOS, 2006, p.5).
\end{abstract}

Entretanto, na anorexia o corpo se esgota para abrir uma falta no outro, e com o indivíduo cada vez mais magro e fraco cabe a ele mesmo fazer-se viver ou não. Silva e Bastos em análise a obra Lacaniana declara que "a partir daí, é ela (a anoréxica) quem depende por seu desejo, é ela quem está à sua mercê, à mercê das manifestações de seu capricho, à mercê da onipotência de si mesma" (SILVA E BASTOS, 2006, p.15). Lacan (1995) aduz que, se a identidade de uma pessoa é adquirida através da linguagem, possivelmente a recusa em falar ou comer, seja uma recusa em atribuir-se a uma identidade como feminina e adulta, por isso o corpo apresentado sempre como infantil.

A partir da teoria psicanalítica, é possível apontar que esta posição subjetiva aponta sua origem na relação entre mãe (ou função materna) e filha, na qual essa última não introjeta a figura feminina adulta na pessoa da mãe, que pode ser vista como algo negativo e consequentemente não deve ser copiada. "O fato é que enquanto o sistema continuar funcionando, a anoréxica se sente bem e maravilhosa, sente-se poderosa, triunfante, excitada. Ela venceu a luta pelo poder sobre si mesma e suas necessidades" (BUCKROVD, 2000, p.35), ou seja, a recusa do alimento mostra-se como uma tentativa de separação do outro ou até mesmo como possibilidade de ter domínio da sua própria vida.

No Rascunho G (sobre a melancolia), Freud postula a Anorexia Nervosa da seguinte forma:

A neurose nutricional paralela à melancolia é a anorexia. A famosa anorexia nervosa das moças jovens, segundo me parece (depois de cuidadosa observação), é uma melancolia em que a sexualidade não se desenvolveu. A paciente afirma que não se alimenta simplesmente porque não tem nenhum apetite; não há qualquer outro motivo. Perda do apetite - em termos sexuais, perda da libido. (FREUD, 1950 [1892-1899]/1976, p. 222-223)

Para concluir, entende-se que a constituição subjetiva e o processo de identificação com o Outro são fatores associados e determinantes quando relacionados ao desenvolvimento da Anorexia Nervosa. Por conseguinte, esse sujeito 


\section{1/02}

ISSN 2178-6925

tido como anoréxica, carrega consigo a falta insuportável do Outro, buscando essa carência posteriormente em situações substitutivas à vivenciada enquanto criança.

\section{Considerações finais}

Mediante o exposto, pode-se afirmar que muitos são os fatores psíquicos contribuintes para o desenvolvimento da Anorexia Nervosa. Desta forma, nota-se que descrever a percurso histórico desse transtorno foi de suma relevância para entender o contexto clínico deste sintoma, uma vez que o comportamento do jejum auto imposto já vem sendo trilhado ao longo da história, na qual tal ato teve sua realização primeiramente pelos povos da antiguidade. Contudo, ao passar dos anos esse transtorno começou a ser questionado em relação a sua prática, pois inicialmente seu objetivo era apenas em exercícios de práticas religiosas, porém com a colaboração de vários estudiosos pode-se certificar que a conduta apresenta um transtorno alimentar.

Do mesmo modo, a compreensão da constituição subjetiva e relações familiares foram fundamentais para alcançar o protagonismo da Anorexia Nervosa, em virtude de que só é possível a existência do ser humano mediante a presença efetiva do Outro, ou seja, o sujeito não pode se constituir sozinho, o progresso da subjetividade necessita de experiências especificas de intersubjetividade. Sendo assim, o sujeito sofre inúmeras influências do núcleo familiar como também do meio social no qual está inserido, tendo isso um total valor para entender o desenlace da Anorexia Nervosa, pois nota-se que a Anoréxica sofre uma enorme interferência da sua relação com o outro no seu processo de constituição.

Portanto, o desenvolvimento da Anorexia Nervosa se dá a partir de todos esses fatores intervenientes, em que a relação e o processo de identificação com a mãe ou quem desenvolve essa função, tem uma vasta atribuição e cooperação para o desdobramento do Transtorno Alimentar. Desta maneira, o autor Sigmund Freud explica que há uma escolha de uma pessoa enquanto objeto de libido, porém, quando essa pessoa não se mostra mais tão disponível para o sujeito, o que possivelmente Ihe causa chateações e frustrações, essa libido é retirada. Apesar disso, ao invés da libido seguir seu processo normal, em que a ela se dirige a outro objeto, o que acontece é o direcionamento da libido para o próprio Eu, ou seja, a libido passa a ser 


\section{1/02}

ISSN 2178-6925

uma identificação do objeto abandonado com o Eu, sendo assim, o desfecho da Anorexia Nervosa é o resultado do conflito entre o objeto e o Eu, onde o objeto é visto como merecedor de ódio, então o Eu se permite a criar sua própria tortura.

\section{Referências}

BARRETTA, João Paulo Fernandes. O complexo de Édipo em Winnicott e Lacan. Psicologia USP, v. 23, n. 1, p. 157-170, 2012.

BRENNER, Charles. Noções básicas de psicanálise: introdução à psicologia psicanalítica. In: Noções básicas de psicanálise: introdução à psicologia psicanalítica. 1987.

BUCKROYD, Julia. Anorexia e bulimia. Grupo Editorial Summus, 2000.

BUSSE, Salvador de Rosis; SILVA, B. L. Transtornos alimentares. Anorexia, bulimia e obesidade. São Paulo: Manole, p. 31-110, 2004.

DO VALE BECHARA, Ana Paula; KOHATSU, Lineu N. Tratamento nutricional da anorexia e da bulimia nervosas: aspectos psicológicos dos pacientes, de suas famílias e das nutricionistas. Vínculo-Revista do NESME, v. 11, n. 2, p. 7-18, 2014.

ELIA, Luciano. O conceito de sujeito. Psicanálise passo a passo. 50. ed. Rio de Janeiro: Jorge Zahar, 2004.

FENDRIK, S. Santa Anorexia. Buenos Aires: Corregidor. 1997.

FERENCZI, Sándor. Transferência e introjeção. Psicanálise I, p. 77-108, 1909.

FREUD, S. Edição Standard Brasileira das Obras Psicológicas Completas de Sigmund Freud. Rio de Janeiro: Imago, 1997.

FREUD, S. Extratos dos documentos dirigidos a Fliess (1950 [1892-1899]). In: Obras Psicológicas Completas de Sigmund Freud. Rio de Janeiro: Imago. 1976. Edição Standard. v. I. p. 243-377.

FREUD, S. Neurose e Psicose. In: Edição Standard Brasileira das Obras Psicológicas Completas de Sigmund Freud: O Ego e o Id e Outros Trabalhos. Volume XIX. Rio de Janeiro: Imago, 1924 [1923]. p. 167-169.

Freud, Sigmund (1917[1915]/1996). Luto e melancolia. (Edição Standard Brasileira das obras psicológicas completas de Sigmund Freud, Vol. 14). Rio de Janeiro: Imago.

FREUD, Sigmund. Três ensaios sobre a teoria da sexualidade, vol. VII. Edição standard brasileira das obras psicológicas completas de Sigmund Freud, 1905. 


\section{$2021 / 02$}

ISSN 2178-6925

FURTADO, LUIS ACHILLES RODRIGUES; VIEIRA, CAMILLA ARAÚJO LOPES. A psicanálise e as fases de organização da libido. Revista Scientia, v. 2, n. 4, p. 93107, 2014.

GOMES, Lilze Franklin Ferreira. O vínculo mãe-bebê e o desenvolvimento do distúrbio alimentar anorexia nervosa. 2008.

HERSCOVICI, C; BAY, L. Anorexia e bulimia: Ameaças à autonomia. Porto Alegre. RS: Artes Médicas., 1997.

KAY, Jerald \& TASMAN, Allan. Transtornos alimentares. In: Psiquiatria: ciência comportamental e fundamentos clínicos. São Paulo: Manole, 2002.

KELNER, Gilda. Transtornos alimentares: um enfoque psicanalítico. Estud. psicanal., Belo Horizonte , n. 27, p. 33-44, ago. 2004 . Disponível em <http://pepsic.bvsalud.org/scielo.php?script=sci_arttext\&pid=S010034372004000100 005\&lng=pt\&nrm=iso $>$. acessos em 29 out. 2019.

KLEIN, M. Amor, culpa e reparação e outros trabalhos 1921-1945. Trad.: André Condoso. Rio de Janeiro: Imago, 1996.

LACAN, Jacques. Seminário IV: A relação de objeto. Rio de Janeiro: Jorge Zahar, 1995.

LINS, Samuel Lincoln Bezerra. Psicose-diagnóstico, conceitos e reforma psiquiátrica. Mental, n. 8, p. 39-52, 2007.

MAGALHÃES, Andrea Seixas; FÉRES-CARNEIRO, Terezinha. Conquistando a herança: sobre o papel da transmissão psíquica familiar no processo de subjetivação. Família e casal: efeitos da contemporaneidade, p. 24-32, 2005.

MAGALHÃES, Belmira; MARIANI, Bethania. Processos de subjetivação e identificação: ideologia e inconsciente. Linguagem em (Dis) curso, v. 10, n. 2, p. 391 408, 2010.

MARKUS, CatiúciaHardt Mayer. Histeria masculina. 2015.

OGDEN, Thomas H.; BERLINER, Claudia. Os sujeitos da psicanálise. Casa do psicólogo, 1996.

PASSOS, Maria Consuêlo; POLAK, Pia Maria. A identificação como dispositivo da constituição do sujeito na família. Mental, Barbacena, v. 2, n. 3, p. 39-50, nov. 2004 .Disponível em <http://pepsic.bvsalud.org/scielo.php?script=sci_arttext\&pid=S1679$44272004000200004 \&$ lng $=$ pt\&nrm=iso $>$. acessos em 24 set. $20 \overline{19}$

PEDROSA, Raquel Lima; TEIXEIRA, Leônia Cavalcante. A perspectiva biomédica dos transtornos alimentares e seus desdobramentos em atendimentospsicológicos. Psicologia USP, v. 26, n. 2, p. 221-230, 2015. 


\section{1/02}

ISSN 2178-6925

POLETTO, Michele. NEUROSE E PSICOSE: semelhanças e diferenças sob a perspectiva freudiana. Psicanalise \& barroco em revista, v. 10, n. 2, 2019.

PONTALIS, Jean-Baptiste; LAPLANCHE, J. Vocabulário da psicanálise. São Paulo: MartinsFontes, 2001.

RADI, L. Vida de Clara de Assis. 11. ed. Aparecida: Santuário, 2015.

SILVA, Alinne Nogueira; BASTOS, Angélica. Anorexia: uma pseudo-separação frente a impasses na alienação e na separação. Psicol. clin. Rio de Janeiro, v. 18, n. 1, p. 97-107, 2006 disponível em $<$ http://www.scielo.br/scielo.php?script=sci_arttext\&pid=S0103-

$56652006000100008 \&$ Ing=en\&nrm=iso >. Acessos em 07 jul 2020

TOREZAN, Zeila C. Facci; AGUIAR, Fernando. O sujeito da psicanálise: particularidades na contemporaneidade. Revista Subjetividades, v. 11, n. 2, p. 525554, 2016.

VIGANO, Carlo. Novas conferências. Carlo Viganó: Novas Conferências. Belo Horizonte, MG: Scriptum livros, 2012.

WEINBERG, Cybelle. Faça ascensão ideal e estética ideal: uma evolução histórica da Anorexia Nervosa. Rev. latinoam. psicopatol. fundam. São Paulo, v. 13,n. 2, p. 224-237, junho de 2010. Disponível em \&lt;http://www.scielo.br/scielo.php?script=sci_arttext\&amp;pid=S1415-

47142010000200005\&amp;Ing=en\&amp;nrm=iso\&gt;. acesso em 29 de maio de 2020. https://doi.org/10.1590/S1415-47142010000200005

WINNICOTT, Donald W. Teoria do relacionamento paterno-infantil. O ambiente e os processos de maturação, p. 38-54, 1983. 
Revista Multidisciplinar do Nordeste Mineiro, v.2 2021/02

ISSN 2178-6925

\section{FICHA DE ACOMPANHAMENTO}

Faculdade Presidente Antônio Carlos de Teófilo Otoni

FICHA DE ACOMPANHAMENTO INDIVIDUAL DE ORIENTAÇĀO DE TCC

Atividade: Trabalho de Conclusăo de Curso - Artigo/Monografia.

Curso: Periodo: Semestre: $2^{\circ}$ Ano: 2020

Professor (a): Paula Lins Khoury

Acadêmica: Ana Karoline de Souza Pereira

\begin{tabular}{|c|c|c|}
\hline \multicolumn{2}{|l|}{ Tema: } & \multirow{2}{*}{$\begin{array}{l}\text { Assinatura do aluno } \\
\text { Ano koroline dis.P }\end{array}$} \\
\hline Data(s) do(s) atendimento(s) & Horário(s) & \\
\hline $29 / 01 / 2020$ & $17 \mathrm{~h}$ & Sha toraline de S. Piviro \\
\hline $15 / 08 / 2020$ & $15 \mathrm{~h}$ & Dro Kotolize aes S. Purira \\
\hline $23 / 09 / 2020$ & $13: 30$ & Anakorotire dis 5. Pswiro \\
\hline $25 / 10 / 2020$ & $17 \mathrm{~h}$ & Ano kardine de 5 . Revito \\
\hline $10 / 11 / 2020$ & $15 \mathrm{~h}$ & Ana Kandine es S Poreiva \\
\hline \multicolumn{3}{|c|}{$\begin{array}{l}\text { Descriçäo das orientaçāes: } \\
\text { Discussäo do projeto preliminar }\end{array}$} \\
\hline \multicolumn{3}{|c|}{ Avaliaçāo da fundamentaçăo teórica } \\
\hline \multicolumn{3}{|c|}{ Discussāo e adequação da metodologia } \\
\hline \multicolumn{2}{|c|}{$\begin{array}{l}\text { Orientação referente à discussão } \\
\text { Avaliaçăo da apresentaçăo gráfica }\end{array}$} & $f$ \\
\hline
\end{tabular}

Considerando a concordância com o trabalho realizado sob minha orientação, AUTORIzO O DEPósıTo do Trabalho de Conclusăo de Curso da Acadèmica Ana Karoline de Souza Pereira.

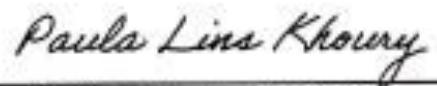




\section{RELATÓRIO DE PLÁGIO}

\section{Relatório do Software Anti-plágio CopySpider}

Para mais detalhes sobre o CopySpider, acesse: https://copyspider.com.br

\section{Instruçōes}

Este relatório apresenta na próxima página uma tabela na qual cada linha associa o conteúdo do arquivo de entrada com um documento encontrado na internet (para "Busca em arquivos da internet") ou do arquivo de entrada com outro arquivo em seu computador (para "Pesquisa em arquivos locais"). A quantidade de termos comuns representa um fator utilizado no cálculo de Similaridade dos arquivos sendo comparados. Quanto maior a quantidade de termos comuns, maior a similaridade entre os arquivos. É importante destacar que o limite de 3\% representa uma estatistica de semelhança e não um "indice de plágio". Por exemplo, documentos que citam de forma direta (transcriçāo) outros documentos, podem ter uma similaridade maior do que $3 \%$ e ainda assim não podem ser caracterizados como plágio. Há sempre a necessidade do avaliador fazer uma análise para decidir se as semelhanças encontradas caracterizam ou não o problema de plágio ou mesmo de erro de formatação ou adequação às normas de referências bibliográficas. Para cada par de arquivos, apresenta-se uma comparação dos termos semelhantes, os quais aparecem em vermelho.

Veja também:

Analisando o resultado do CopySpider

Qual o percentual aceitável para ser considerado plágio?

Importante ressaltar que os plágios apontados pelo programa foram decorrentes ao artigo da própria aluna que foi publicado no e-book, conforme pode ser verificado abaixo:

\section{Psicologia: Compreensão Teórica e Intervenção Prática 3}

DOI: $10.22533 /$ at.ed.634200710

ISBN: $978-65-5706-463-4$

PALAVRAS CHAVE: 1. PSICOLOGIA. I. MATOS, TALLYS NEWTON FERNANDES DE (ORGANIZADOR). I TITULO.

ANO: 2020

CAPITULO 1. .1

PERSPECTIVA PSICANALÍTICA DA ANOREXIA NERVOSA

Ana Karoline de Souza Pereira

Paula Lins Khoury

DOI 10.22533/at.ed.6342007101 
Revista Multidisciplinar do Nordeste Mineiro, v.2

2021/02

ISSN 2178-6925

CopySpider

hitips/licopyspider.com.bril

Page 2 of 132

Relatório gerado por: yararro@gmail.com

Arquivos

Termos comuns Similaridade

TCC. ANA KAROLINE doc $X$

hitips/WWw finersistemas.com/atenaeditora/index.php/admin/ap

VartigoPDF/40856

TCC-ANA KAROLINE doCX X

htips:/Www atenaeditora. com bripost-artigo/40856

\begin{tabular}{lll}
\hline TCC. ANA KAROLINE. doc $X$ & 4641 & 5.28
\end{tabular}

htips/WWW finersistemas.com/atenaeditoralindex php/admin/ap

VebookPDF/3564

TCC-ANA KAROLINE.doc $X$

https:lilrepositorio.unb.br/bitstream/10482/16212/1/ARTIGO_De

sempenhoOrganizacionalRelacoes.pdf

TCC. ANA KAROLINE. doc $X$

https//www. mdsaude.com/priquiatria/anorexia-nervosa

TCC.ANA KAROLINE.docX X

http:J/pepsic.bvsalud.org/scielo.php?script=gci_arttext\&pid=S01

03-84862012000300001

TCC-ANA KAROLINE. doc $X$

http:/scielo.iec gov briscielo.php?script=sci arttext\&pid=S1679.

4581

53,14

49742014000300001

TCC. ANA KAROLINE. doc $x$

https//Www. passeidireto.com/arquivo/71563149/hitp-www-

491

scielo-br-scielo-php-script-sci-arttext-pid-5-0104-

40602019000100287

TCC-ANA KAROLINE. doc $X$

74

https:/Www.scielosp.org

TCC. ANA KAROLINE doc X X

39

httos:/lscielo.org 